The Journal of Public Space

ISSN 2206-9658

2018 | Vol. 3 n. 2

City Space

https://www.journalpublicspace.org

\title{
Art as a tool for change
}

Javier Serrano Guerra, Juan Jaume Fernández, Pablo Ferreiro Mederos, Pablo Purón Carrillo

\author{
Boa Mistura \\ hola@boamistura.com
}

\begin{abstract}
Each of the more than twenty countries in which we have worked represents a unique experience that has made us learn and gradually generate a participatory methodology in which we involve communities not only in the design process but in the execution of a urban art piece. More than fifteen years of work with the aim of humanizing the city and generating great changes from simple artistic activities.
\end{abstract}

Keywords: urban art, change, participation, inspiration, identity

\section{To cite this article:}

Guerra, J. S., Fernández, J. J., Mederos, P. F., Carrillo, P. P. (2018). Art as a tool for change. The Journal of Public Space, 3(2), I3-40, DOI I0.3289I/jps.v3i2. I 108

This article has been accepted for publication in The Journal of Public Space. Please see the Editorial Policies under the 'About' section of the journal website for further information. 
More than fifteen years have gone since we painted our first murals on the streets of our neighbourhood in Madrid to this day, freshly landed back in Madrid from the $9^{\text {th }}$ World Urban Forum in Kuala Lumpur. Much learning and personal evolution separate us from our first works. When, at the end of the $90 \mathrm{~s}$, we got together in our neighbourhood in the outskirts of Madrid to paint graffiti, we could never have imagined the many experiences that we would have the opportunity to live around the world, thanks to it. Our trip started in a very spontaneous way, while we shared our free afternoons as high school students. Graffiti was our common point and the way we had fun. A few years later, each of us followed a different path in college. We are formed as Artists, Advertisers, Architects and Civil Engineers, but always finding time to get together to paint in the street, being more and more aware of how much we liked that.

When we finished our university studies, climbing on a crane painting twenty five meters above ground in Berlin, we made the decision to join forces to devote ourselves completely to what we liked the most. We rented a small studio space in the heart of Madrid, which is still our refuge today. Little by little, the first job opportunities began to emerge, and we took 'Boa Mistura' as the collective name. For us, this Portuguese word meaning 'good mix' represents the loss of each one's personal ego. Boa Mistura is the union of our abilities and interests always in favour of a common result.

We began to dedicate every hour in the day, and every day of the week, to designing and painting, maturing and evolving different lines of work, feeling more and more comfortable with the job we created. In 20 II, an opportunity came to us that changed our way of understanding our work forever: we were invited by Ricky Lee Gordon, gallery owner and South African urban artist to make an artistic residency in Cape Town. There we had the opportunity to know the township of Khayelitsha, one of the largest slums in South Africa, inhabited by some 400,000 people in very basic metal houses. It was the first time we faced a reality like that. Despite the need, the shortcomings and the social problems, we were fascinated by the strong sense of unity and community of those people.

There we were able to intervene in the barracks of the Velokhaya cycling school, a cultural and sports centre that has become a refuge for many young people in the community, helping them to escape from their complicated family situations.

Amos, the founder of the school and a natural-born community leader, encouraged all of the students to participate in the painting process. This was the first time we opened our working process to other people. We painted accompanied by dozens of kids and neighbourhood volunteers. It was a real turning point in our career: we realized that when people participate personally in the process of transformation of the place they live, they begin to feel proud of it. If they are able to change their environment, why not change other negative aspects that surround their lives?

They told us in the Woodstock neighbourhood:

"Changes, however small, can generate big changes. Maybe it's your job. What you are going to do here, can be the spark that ignites this great change".

This is how the Crossroads project was born.

From then on, and whenever possible, we consciously try to include the local community of the site in our work methodology, both in the process of collecting ideas for design 
and in the execution. In addition, we often elaborate more than one proposal so that they are the ones who choose by voting which of them will be the one that is finally executed. For us, it is not only about sensitizing the inhabitants, it is also about being transparent and generating a participatory process both in the identification and in the formulation of the work.

Since we passed through South Africa, we have visited more than 20 countries putting into practice what we have learned, learning new things and adding new layers to our work: from the favelas of Sao Paulo in Brazil, to the overpopulated cities of China; from the narrow lanes of the Casbah (old city) of Algeria to the arid boundaries of the Atacama desert in Antofagasta, Chile; from Bogotá, the massive hives inhabited by displaced people of the armed conflict of Colombia to the blocks of the periphery of Guadalajara, in Mexico. Each of these places have represented a unique and completely new experience, but at the same time we find that there is a discourse that unites the lives of all the people who inhabit them.

Each of those places has told us a story of overcoming and courage, the story of people in the most vulnerable situations and often forgotten by institutions, who struggle every day to build a community and protect their values. We, through our work, simply try to reinforce their identity and promote change through colour, but it is always us who take the greatest learning. Now we know that everyone, regardless of where they were born or what their life is like, has an enormous potential inside that deserves to share with the world. We call it "the diamond inside", once again, taken from the learning that our experience in South Africa implied.

We have understood that in our work, when living in the street, the human factor is something of capital importance.

We seek inspiration in people, to generate works that in turn inspire others and thus, in a kind of loop, humanize this world in which we live.

We use painting as a tool to dignify the space and completely modify the urban landscape, giving it a new story. We find paint interesting as a work tool because of its enormous evocative power and the immediacy of results. There is no quicker and simpler way to completely alter a place. It is universal and accessible to everyone. No specific training is needed to apply it, and it has a very playful nature, so it is a perfect tool to stimulate participation in our projects.

One of the things that we preserve from our roots in the world of graffiti is the perception of the street as the best scenario in which we can intervene: it is a free space, spontaneous and constantly changing. In the street there are no intermediaries between the receiver and the art piece. For us, urban art in the city is no more than a reflection of a healthy society that knows how to express its ideas in a creative way. That is why we are attracted by the idea that our works are part of the public space, we want to add our point of view to the common story of our time.

After several years working in the street we have realized that often, the way in which the planning of new urban infrastructures is addressed is not usually very sensitive to the urban fabric in which it is inserted. This has resulted in urban barriers, residual zones and areas of marginality.

For us, being able to live in a friendly and humanized environment is a right for all and that is why we focus precisely on those points of conflict and stigmatization. We want to make the city a place of interaction, at the service of people and with the ability to convey a 
message of empowerment and optimism. We have to be aware that the aesthetics of everything around us influences our lives and our state of mind.

The noise, the smells, the speed, the culture and the overdose of stimuli are implicit concepts in the life of the cities. We take all that information and use it as a creative base to play and generate a beautiful message.

"If you live surrounded by trash and dirt, that's what you will feel inside you".

Another lesson we take from Cape Town.

The permanence in time does not worry us, we assume that it is something characteristic of urban development. The ephemeral nature of art seems beautiful and romantic to us, it flows with the history of spaces. Our work is alive, and like any living being, it is born, ages and ends up dying.

For us the most important thing is that the work is connected in some way to the specific enclave, so that it only makes sense there. Therefore, before starting to sketch the design, we do a previous research work to immerse in the place, the culture and the people that make up the community where the work will remain anchored. We like that it is the locals themselves who give us their perspectives of the context and from here we start to build a work that is coherent with all that wealth. We try that the final result articulates a dialogue with the place and the people who will live with it.

Sometimes we underestimate the capacity for transformation of small actions, but a layer of paint of barely a few millimetres thick can change the perception that a whole neighbourhood has of a place, and that is something we have learned from experience. A good example of this was our visit to Hamar, in Norway, where we intervened in I 200sqm of pavement used as parking to reclaim it as a space for people. We were inspired by the Scandinavian fabric prints, which the Norwegians wore so proud, and we put a jersey in the square. With that spot of colour, the inhabitants of the area began to perceive and use the esplanade as a plaza. Thanks to that first artistic experience, the transition to create a true square in that space, with the help of several groups of architects and town planners, was much simpler.

The same happens with one of our latest works: Nierika, located in the Mexican city of Guadalajara. When we now see that colossal space of colour where children play, it is hard to imagine that just a few months ago it was a degraded and desert place where the sale of drugs proliferated.

We remembered arriving there with empty hands and that immediately the exuberance of the Mexican culture overwhelmed us. The violent colours of its painting, the infinite extension of the cities, the hospitality of its people, its thousands of sounds and flavours and its historical legacy. We wanted to take a bit of all that strength to a space that seemed to have lost its identity. And as always, it was the residents of the Infonavit Independencia neighbourhood that helped us channel all these ideas into three powerful words that we drew on the facades that face the square: FUI, SOY, SERÉ. (I was, I am, I will be). Past, present and future.

As a common thread, we use the iconography of the Wixárica culture, native of northern Jalisco.

The Nierikas are for the Wixárika people trans generational mirrors that allow them to 
communicate with their ancestors to guide their steps in a firm and successful way towards the future.

Therefore, we use shapes and colours inspired by these Nierikas to draw, from the floor of the immense square, the three screaming words in the buildings that surround it, as a call to pride, to keep alive the identity that differentiates us as people, neighbourhood or culture, in the generations to come.

Once the concept of the project was decided, we faced those 4500 sqm with the help of several unemployed residents of the neighbourhood, volunteers from the neighbourhood and several groups of students from the University of Guadalajara. The process provided a unique opportunity for interaction between very different people for several weeks. For that reason only, for us the project has already been a success.

At the end of the execution, that abandoned esplanade has become the new meeting point in the neighbourhood and one important landmark in the city. It is a place where conferences, concerts, flea markets and picnics take place. We said goodbye to the square as proud parents, happy to have been present in that exciting moment of change. It is a work that no longer belongs to us but has a life of its own.

We love what we do.

We do not know how to live in another way. Today, the studio has grown (we are currently seven people in the team) and, with it, the desire to continue giving a spin to that wheel of inspiration that is our job.

We continue working with the same enthusiasm and the same desire as those kids who met on weekends in the streets of their neighbourhood. We continue to learn and get excited in every place we go, so, as long as there is fuel in the engine, we will continue with this adventure called Boa Mistura. 
Art as a tool for change

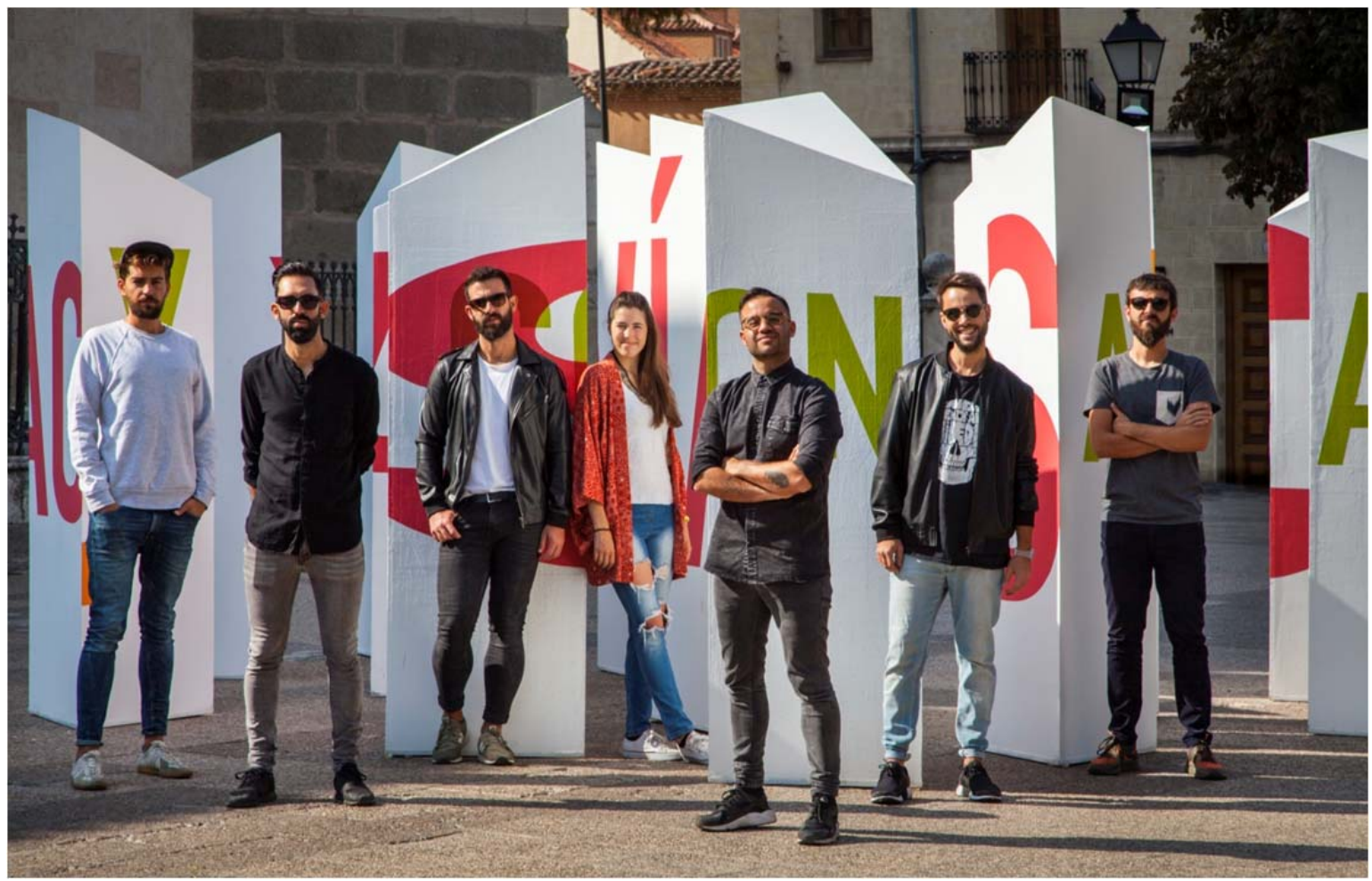

Boa Mistura is a multidisciplinary team with roots in graffiti art. Born in late 200I, Madrid, Spain. The term 'Boa Mistura' comes from the Portuguese 'good mixture', referring to the diversity of backgrounds and points of view from each member. We were fifteen years old when we first met, while painting the walls of our neighbourhood. We became friends since then. We painted our first mural in the late $200 \mathrm{I}$ and in January 2010 we opened our own studio in Madrid, where we work hard with passion and love. We develop our work mainly in the public space. We have carried out projects in South Africa, USA, UK, Brazil, Mexico, Georgia, Chile, Algeria, Norway, Kenya, China, Serbia or Panamá. Our headquarters is in Madrid, but we spend the day from here to there, living among paint buckets, computers and ping-pong matches.

We love what we do. We understand our work, as a tool to transform the street and to create bonds between people. We feel a responsibility with the city and time we are living in.

http://www.boamistura.com 


\section{NIERIKA}

Guadalajara, Mexico. November 2017

http://www.boamistura.com/\#/project/nierika

The housing is located at the north of Guadalajara.

It is estimated to have around 2.500 inhabitants, living in 1.024 apartments, distributed in 66 similar towers. It was built by the Infonavit in the early 80 's and today represents one of the several stigmatized areas of the city, due to the explicit drug dealing problem.

The neighbors tells us that the Municipality has never allocated economic resources to its maintenance. Our perception is that of an abandoned place, with a very complex living dynamic, but with a lot of possibilities to work in order to reverse this dynamic, creating a new usage memory among the neighbors and create appropriation.

The project covers 1000 sqm of the sport courts, while the facades of the buildings are almost $5000 \mathrm{sqm}$, distributed among three buildings, two facades and a huge floor that have become one of the most depressed areas of the Colonia Infonavit Independencia in a large square for neighbors.

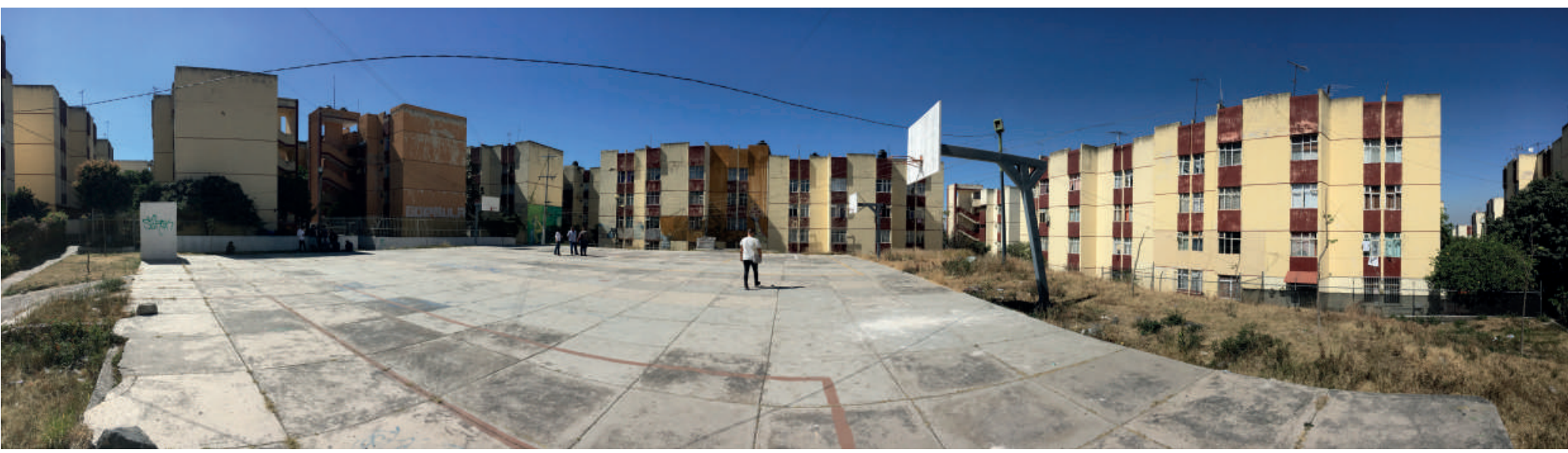

The creation process has included the community since the beginning of the project, in January 2017, through some surveys that inspired two lines of work that were put to a vote among the neighbors, being they themselves who chose what was going to be painted in their place. During the execution, carried out during November 2017, five neighbors were hired in unemployment to be part of the team, in addition to the many neighbors who joined selflessly, as well as students from the University of Guadalajara, who accompanied the process of principle to end.

The work is based on the wixárika worldview, the majority indigenous people in the Jalisco area and the adjacent states. In the wixárika universe, everything is related, everything and everyone is in constant communication. People, plants, animals, the Sun, the air, water, the earth ... all together we are part of the same universe, full of links that unite us with each other. That is why, for this concept of community, by the strength of community bonds to understand the world and by geographical proximity, we have chosen the Wixárika people as inspiration for our work.

The NIERIKA is the transgenerational mirror of the wixaricas. An amalgam of energy that prolongs the wisdom of the ancestors in the following generations, and guide them to build the future. 

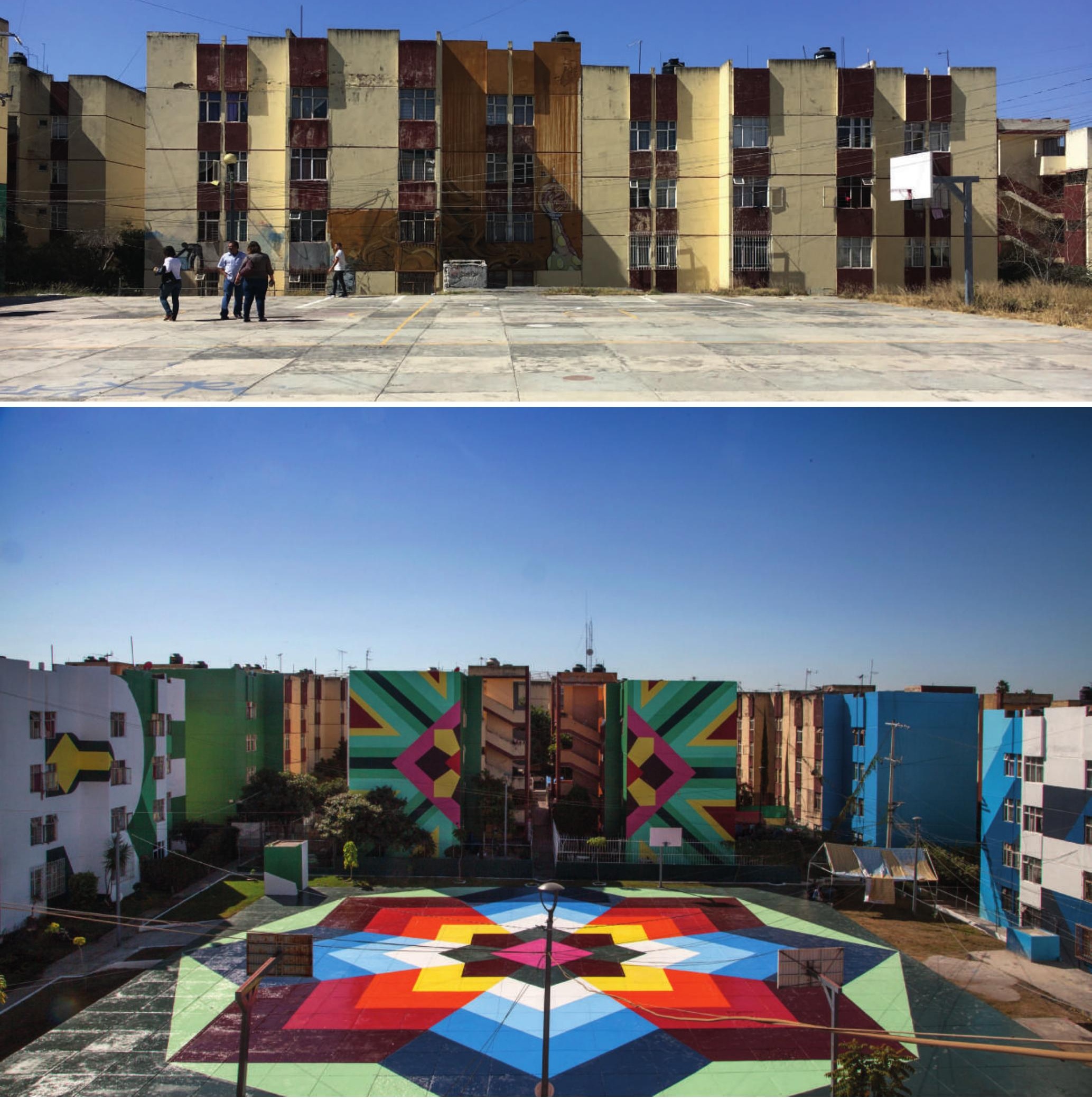

20 | The Journal of Public Space, 3 (2), 2018 | ISSN 2206-9658

City Space Architecture / UN-Habitat 
"The niérika allows the wixaritari to put order in their daily life, to live in unity in a world in which, otherwise, it would be chaotic and unpredictable. It also allows them to relate the present with the past, and, for this reason, it allows them to live with awareness of their history and know that they are the ones who will design their own future."

Luz Chapela

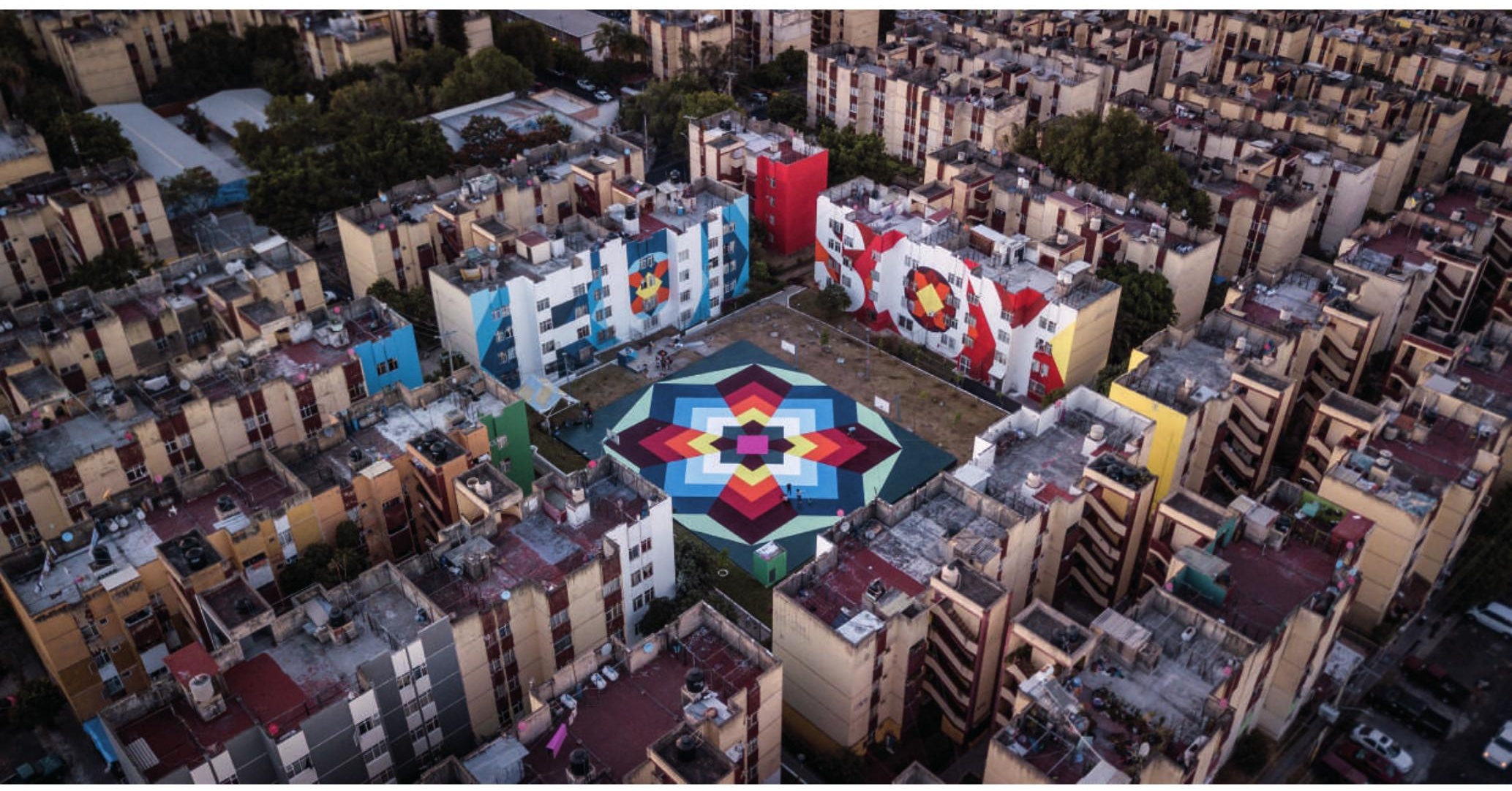

FUI, SOY, SERÉ (I was, I am, I will be) are the words that shout the three facades that surround the plaza, and that represent the strength of the identity of the Mexican people. The richness of his past, the firmness to keep him alive in the present and the knowledge that in the hands of the people of today is keeping his identity beating in the future. One of the main instruments of the niérika, is the Hi'ikuri (Peyote). In the work, two of the main instruments to access the Nierika are also represented: On the two central facades, the Hi'íkuri, as the peyote is called in the Wixárika culture. Its ritual consumption is associated with the ability to see, to understand the world from the divine revelations. It provides a way to understand the world beyond the obvious.

On the floor of the square, the Tsi + kri, a Nierika of utmost importance.

Legend has it wixárika that Kayumarie, one of the gods of creation, looked through the Tsik + ri to see the world in its entirety, and know that it was exactly what he wanted to create. It also serves as a guide and as an element of protection. 


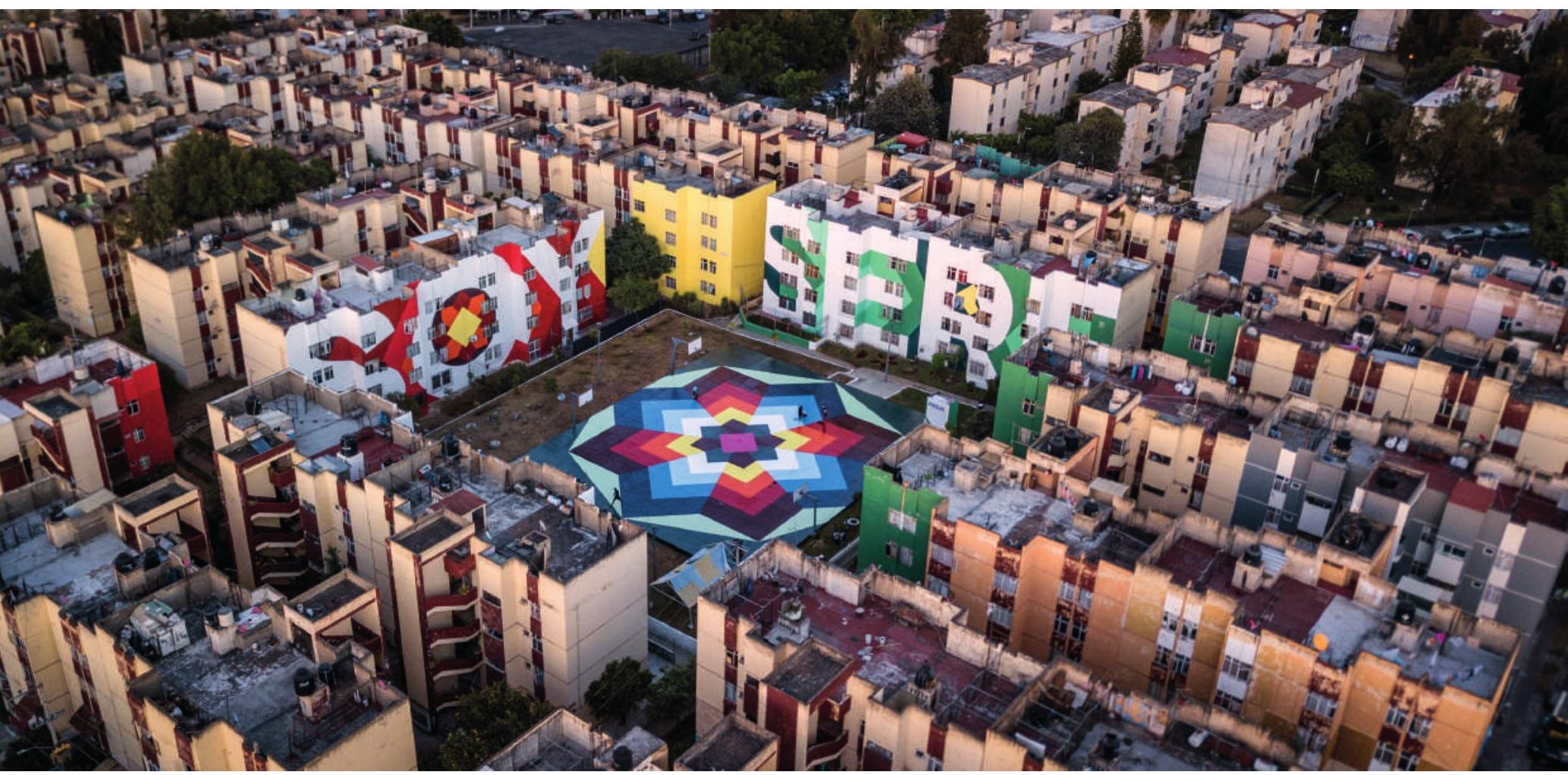

The color in the Wixárika culture is also a guide, and an element of protection. The colors of the work make reference to the fundamental triad of the wixárika conception:

Blue:TUTUTZI MAXA KWAXI (The creador)

Red:TATEWARI (God of fire)

Green:TUKUTZI NAKAWE (Grandmother Earth)

The process has been developed together with the Department of Culture of Guadalajara, that took the challenge of activate the area through "Cultura Itinerante" activities, "Arte sin Paredes" and "Festival Sucede". The goal was to settle a more open social fabric, capable of embrace outside incentives, and prepare the community for the upcoming project.

Our first contact with the neighbors was through one of the surveys that let us to study the context of the area and create two design options. After that, both design options were presented to the neighbors, so that they could vote. They finally chose Nierika. The last stage was the execution, and also was conceived collaboratively. Six unemployed neighbors were instructed to work in heights, and then hired to work with us.

As Nierika, we felt the work and it's development like a transgenerational mirror. A place built on bridges between different social realities working together. This way of building cities should be a model today, in order to develop the society of the future.

\section{Credits}

The work has been possible thanks to the support of the Madrid City Council, Guadalajara City Council, FIL Guadalajara, Pinturas Prisa and, in particular, to the unconditional support of the residents of the Infonavit Independencia Housing Unit and the volunteers of the University of Guadalajara. 


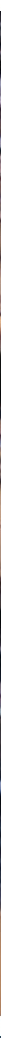



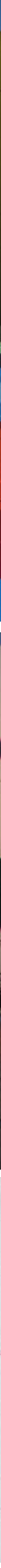

24 | The Journal of Public Space, 3 (2), 2018 | ISSN 2206-9658

City Space Architecture / UN-Habitat 
Javier Serrano Guerra, Juan Jaume Fernández, Pablo Ferreiro Mederos, Pablo Purón Carrillo

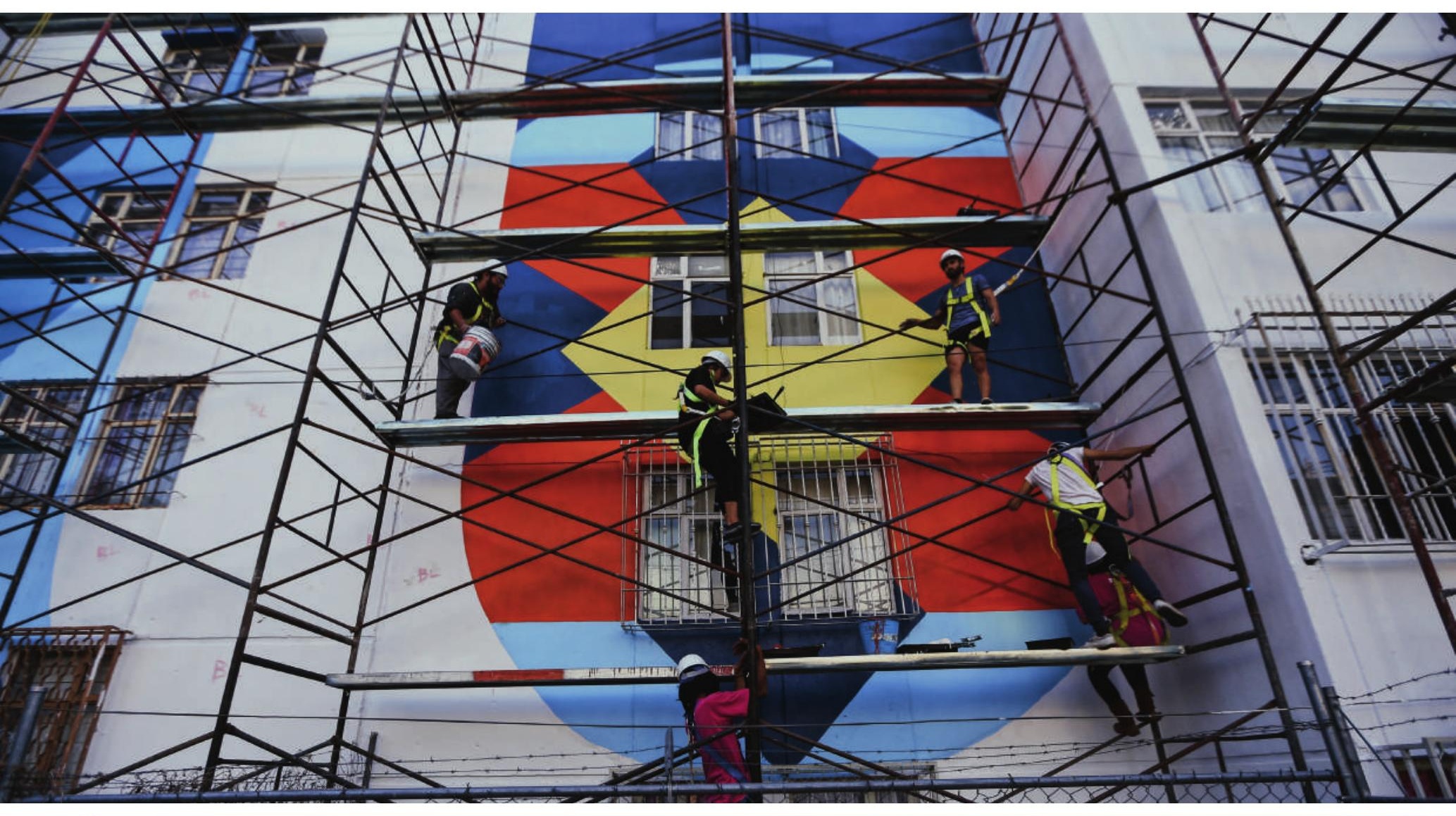




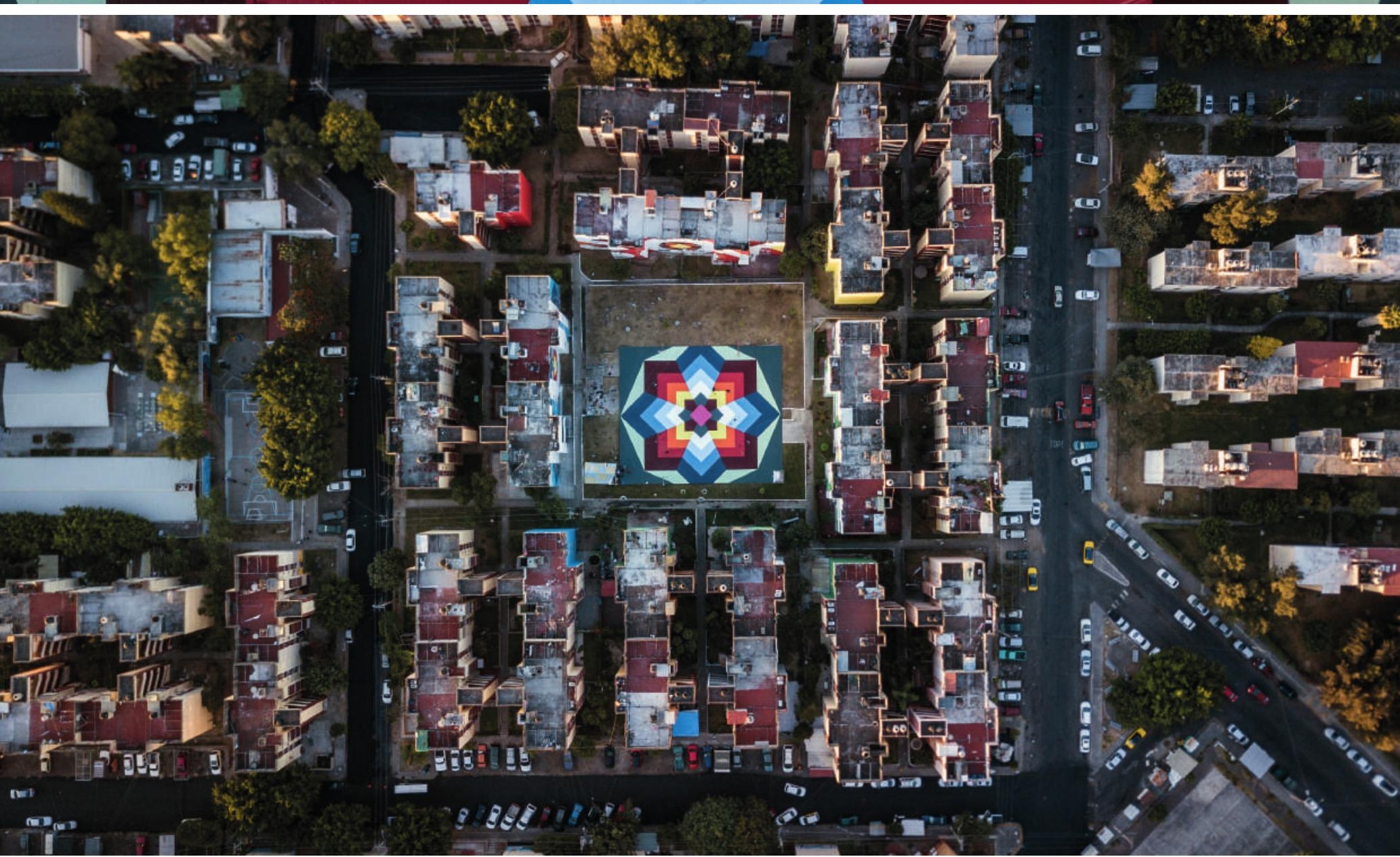

26 | The Journal of Public Space, 3 (2), 2018 | ISSN 2206-9658

City Space Architecture / UN-Habitat 


\section{SISI NI MASHUJAA}

Kibera, Kenya, 2016

http://www.boamistura.com/\#/project/sisi-ni-mashujaa

In January 2016 Boa Mistura travelled to Nairobi, Keniy, developing a project in one of the biggest slums in Africa, Kibera, in which several million people survive each day with less than $I €$ per day.

Kibera means 'woods' and before in the $X X$ century it was a field near Nairobi. The first impact is overwhelming: stench, stagnant water, plastic mountains, animals eating from the trash, houses made up by enticing you can imagine, trenches but most of all mud.

Once you overcome the impact, you discover a totally different universe. A cohesive community, creative and alive. With so much force within it, that looks at life with their eyes quite open, teaching the young that spirit of survival that we haven't seen elsewhere. The best way to describe Kibera is by describing the children's smiles and the way the shout "MZUNGU, MUZUNGU" ("white man", in Swahili) every time they see you.
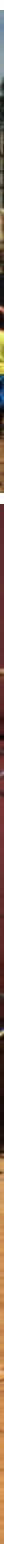

27 | The Journal of Public Space, 3 (2), 2018 | ISSN 2206-9658

City Space Architecture / UN-Habitat 


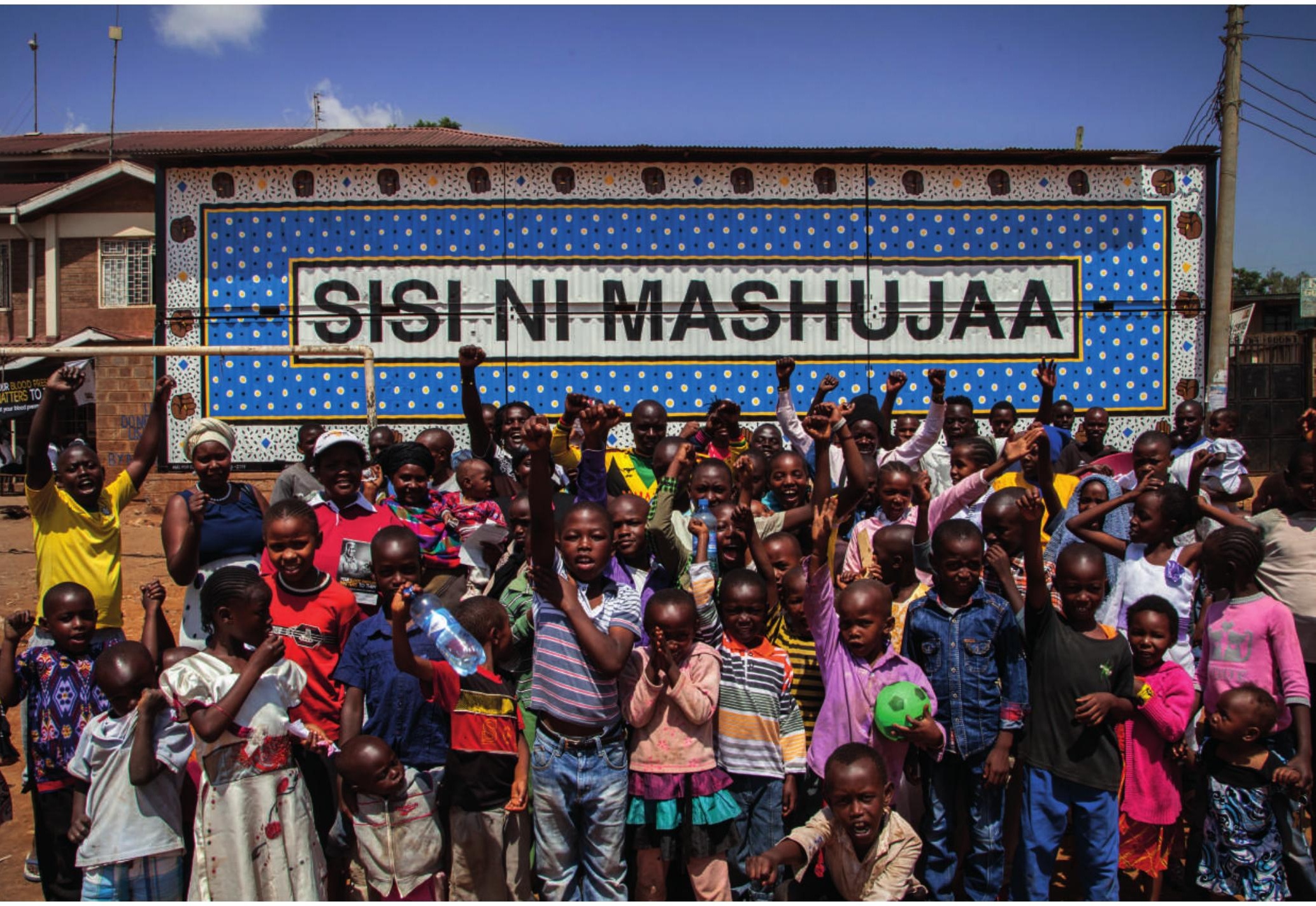

Our project is a reflection of the strength that all the neighbors show every day. It is a tribute to the smile, optimism and determination from every woman and man, to go on with their lives despite the hard conditions.

We have worked over the 6 containers from AMREF hospital at the Laini Saba ground. The only kind of "Open Park" at the township. A space of $2.500 \mathrm{~m} / 2$ in which every day thousands of people walk passing through or to play football or turning into a market or the playground of the three schools that are near it.

It is the greatest witness of the life in Kibera and probably the only public space that could be called square.

The Leso or Khanga is a type of cloth that women use in all of the east of Africa. Within its print, there is always a text that sends a message that accompanies you day by day. Women choose the fabric because of its colors, but especially because of the message. There was not a better tribute to all of Kibera's inhabitants than to dress up AMREF's hospital with this Leso that says:

SISI NI MASHUJAA which in Swahili means

"We are heroes". 
Javier Serrano Guerra, Juan Jaume Fernández, Pablo Ferreiro Mederos, Pablo Purón Carrillo
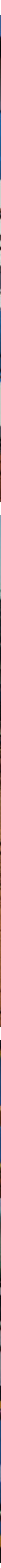

29 | The Journal of Public Space, 3 (2), 2018 | ISSN 2206-9658

City Space Architecture / UN-Habitat 

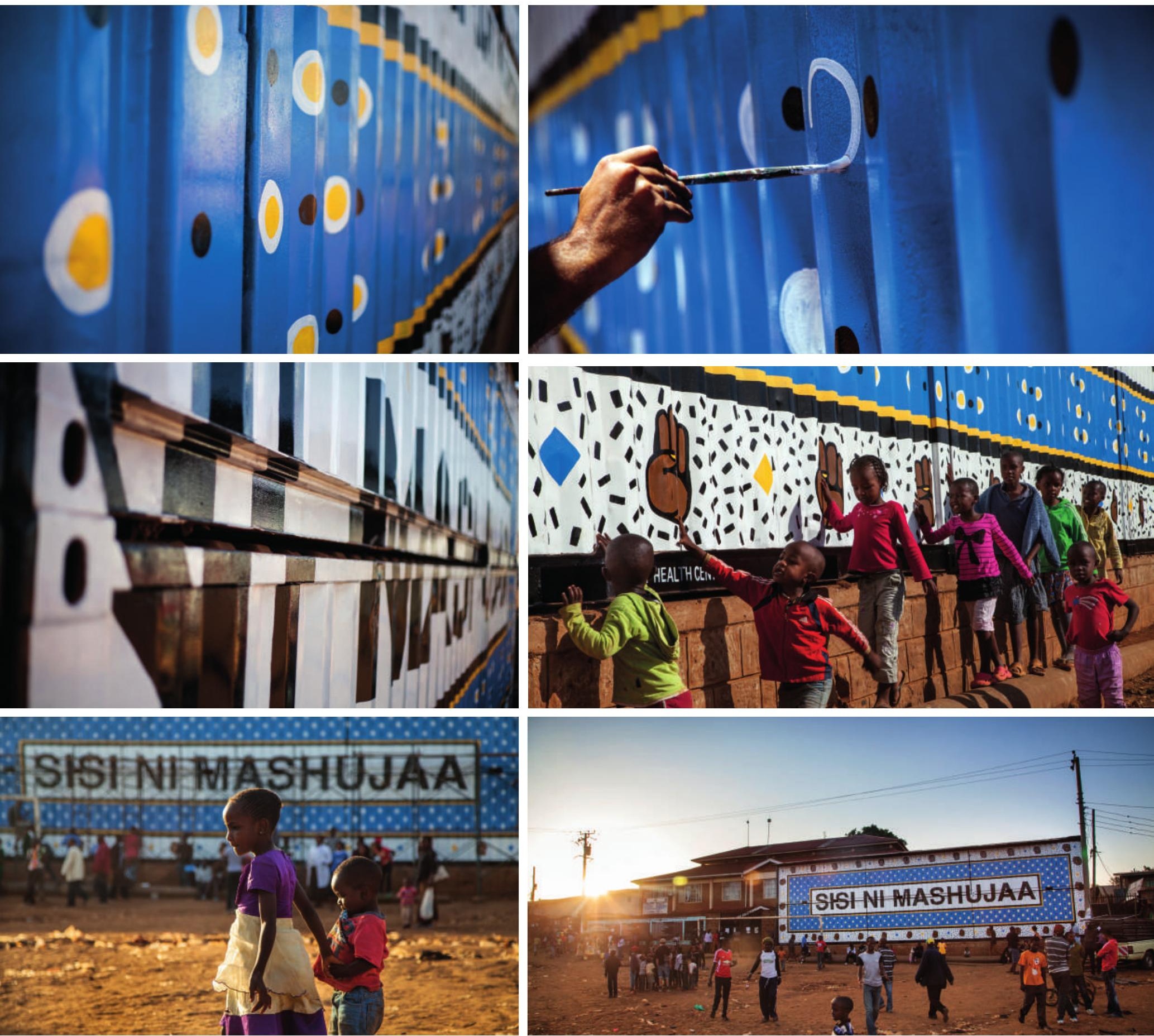

\section{Credits}

I00sqm of mural executed over the containers of the AMREF hospital in the Laini Saba ground at Kibera. The Project has being possible thanks to the healp of "Ghetto Youth Focus Foundation" GYFF, Made in Kibera, Kubura Mas Por Ellos and the support of Renault. Special thanks to Geoffrey, Phlexible, Simon aka Twaani, Coco Tea, Cleophas, Denise, and Warrá for being our guardian angels in the slum. To Andrea, Luis, Carra, Miriam, Raffi, Álvaro and Jose Luis for being our family in Kibera.

Thanks to all the community of Kibera for inspiring us and make us remember the true values in life. 


\section{DREAM HAMAR}

Hamar, Norway. 20I I

http://www.boamistura.com/\#/project/dream-hamar

Hamar is the third largest city in Norway. It is located inland, at the shore of the Mjøsa lake, the soul of the city.

Stortorget is the Norwegian term used to discuss the main space for relationship, a word we understand as public space or square. In this case, the rise of automobile made Stortorget, the city's main parking lot, losing its original use thought as a space for interaction. The architects' firm Ecosistema Urbano proposed a collaborative process to redesign the square.
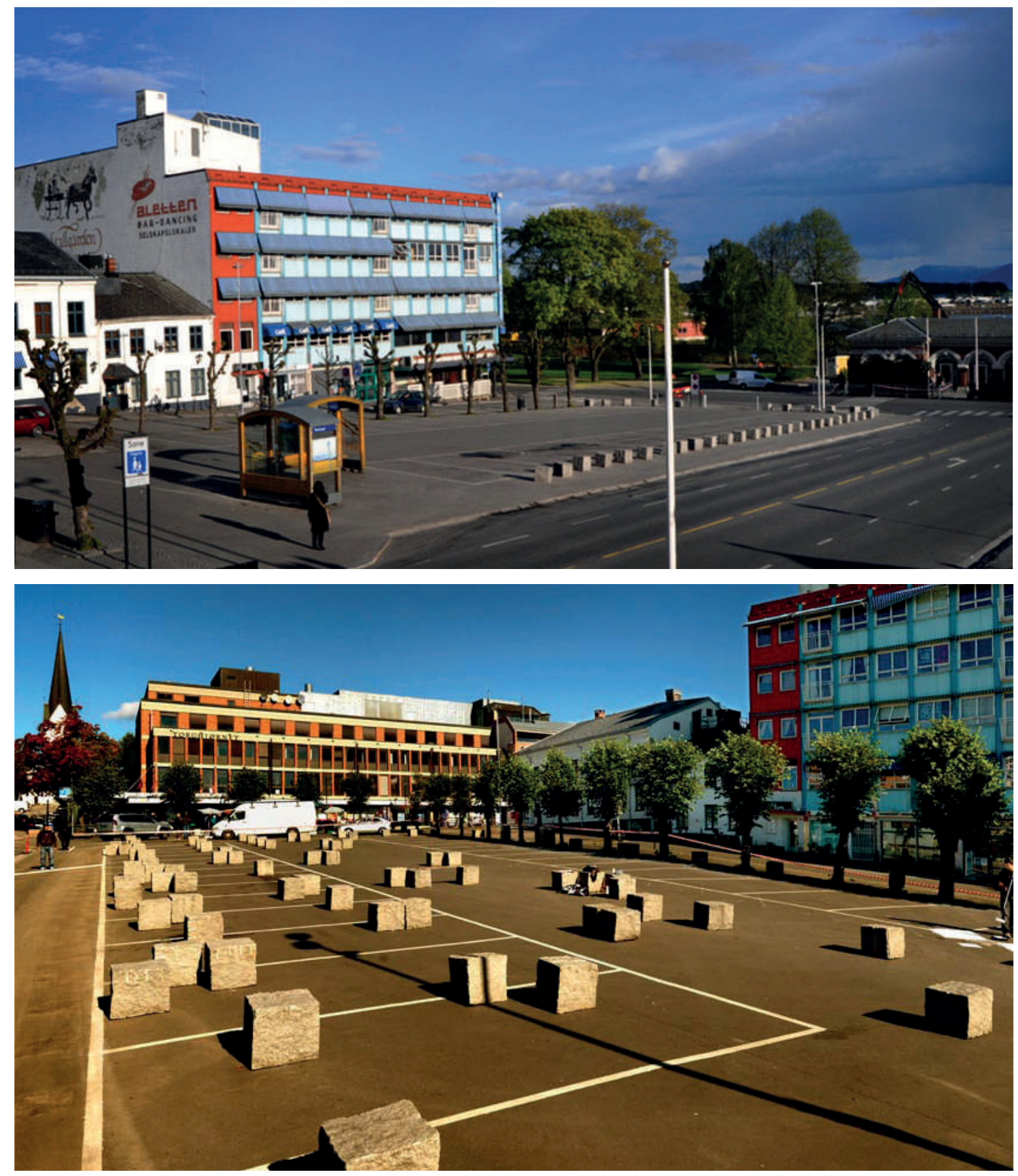

3I The Journal of Public Space, 3 (2), 2018 | ISSN 2206-9658 City Space Architecture / UN-Habitat 


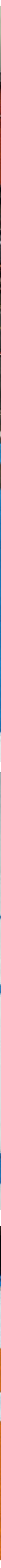

32 | The Journal of Public Space, 3 (2), 2018 | ISSN 2206-9658

City Space Architecture / UN-Habitat 


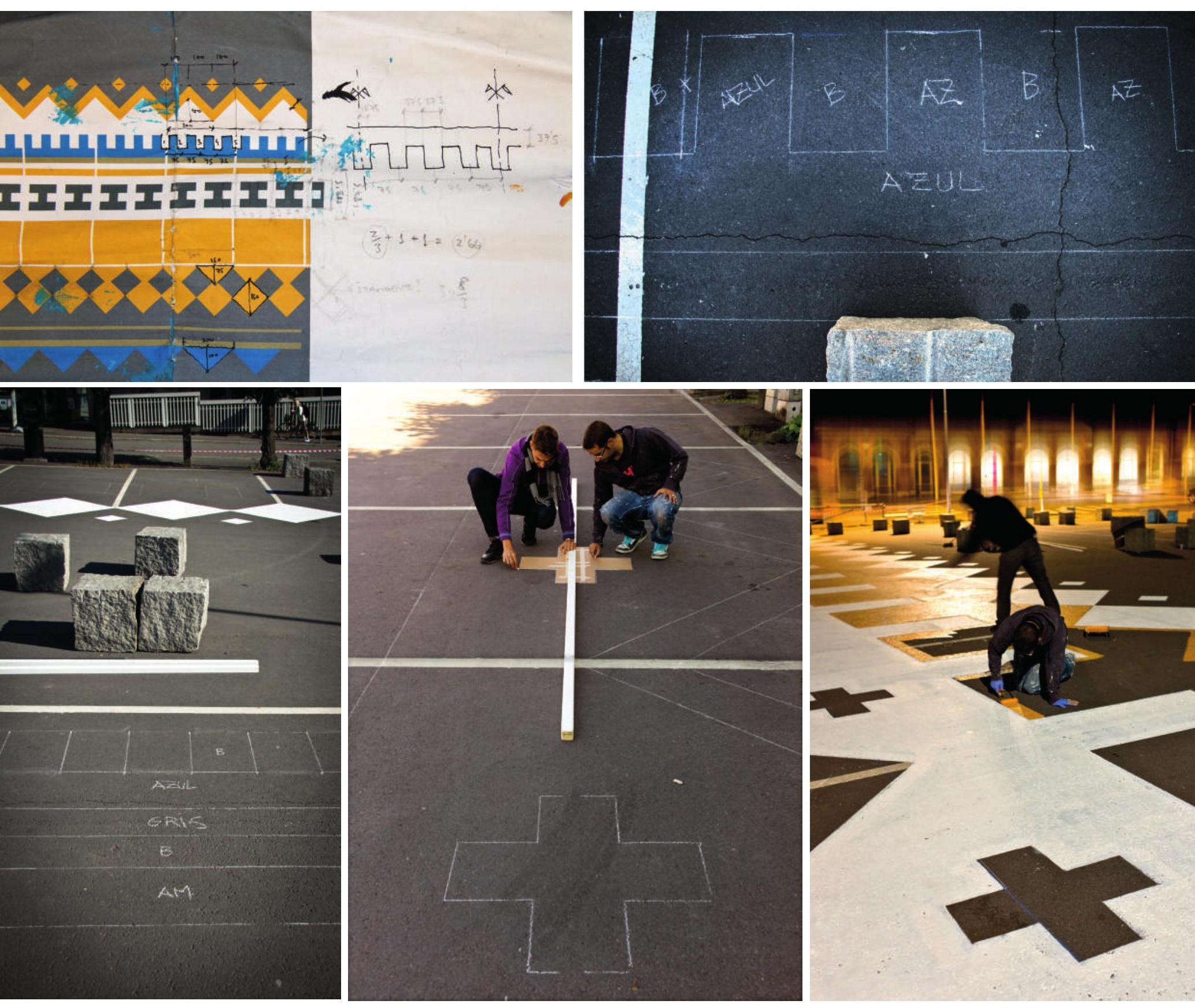

Our intervention consisted on painting the 1500 sqm floor of the square, getting it back for the citizen. We made a contemporary interpretation of the traditional Norwegian patterns, that inspired us to weave a new "blanket". The work area is the city's main square, turned nowadays into a parking lot. The space is surrounded by 37 granite cubes which enclosure the square, only leaving some space for the car access.

Just a few days in the city helped us to appreciate the love that Hamar's inhabitants have for their patterns, which decorate their hats, globes, socks and sweaters.

These clothes are everywhere and are a sign of identity. We studied the origins and the most important designers that have worked with these patterns, so we could remake them and create a new and colored geometry composition.

The first decision was to scatter the bollards, making the area not usable for the cars and setting the space ready for its new use. Then the paint arrived. 


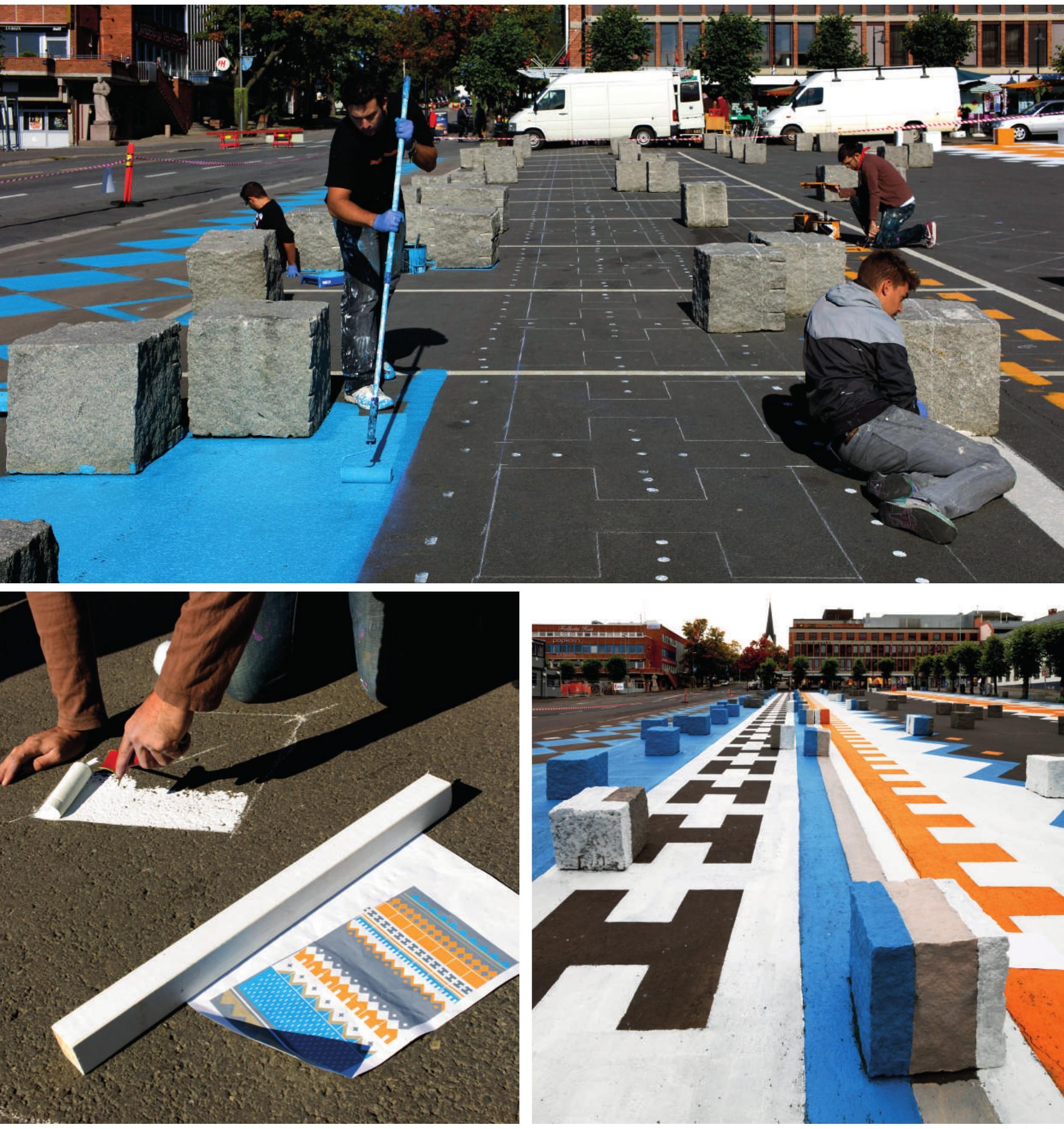

\section{Credits}

Thanks to José Luis Vallejo y Belinda Tato for trusting in us. And all the Ecosistema Urbano team for the support.

34 | The Journal of Public Space, 3 (2), 2018 | ISSN 2206-9658

City Space Architecture / UN-Habitat 


\section{GEOLOGICAL SKIN}

Antofagasta, Chile, 2016

http://www.boamistura.com/\#/project/piel-geologica

Antofagasta is located at the north of Chile, in the second region, being the doors of the Atacama desert. It is a very particular city, developed lengthways following a North-South direction. Is spreads among the narrow space of only $2.5 \mathrm{~km}$ between the first Andes and the Pacific Ocean. It was built based on the mining, that make use of the extremely rich composition of the upland soil.

The neighborhood of René Schneider at the East side of the city, making direct contact with the hills of the early Andes, arises from an informal appropriation of the territory, in what the Chilean call "tomas". A group of new neighbors join together to adapt a terrain and install their new homes. Firstly with tents, then substituted with wooden pieces, metallic sheets and prefab concrete blocks.

The intervention is focused on Serrano with Alfonso Meléndez street, both inside René Schneider neighborhood, at the city of Antofagasta, Chile.Almost 40 houses and 4.000 square meters that completely modifies the appearance of this community, making it visible from the center of the city.

It is framed in the plan of strategic actions from the institution CREO Antofagasta, which aims to reinforce the connectivity between different urban cores of the city. The project takes on the challenge of working hand to hand with a selected group of local artists and neighbors, with the intention of leaving a seed that might grow in the future.

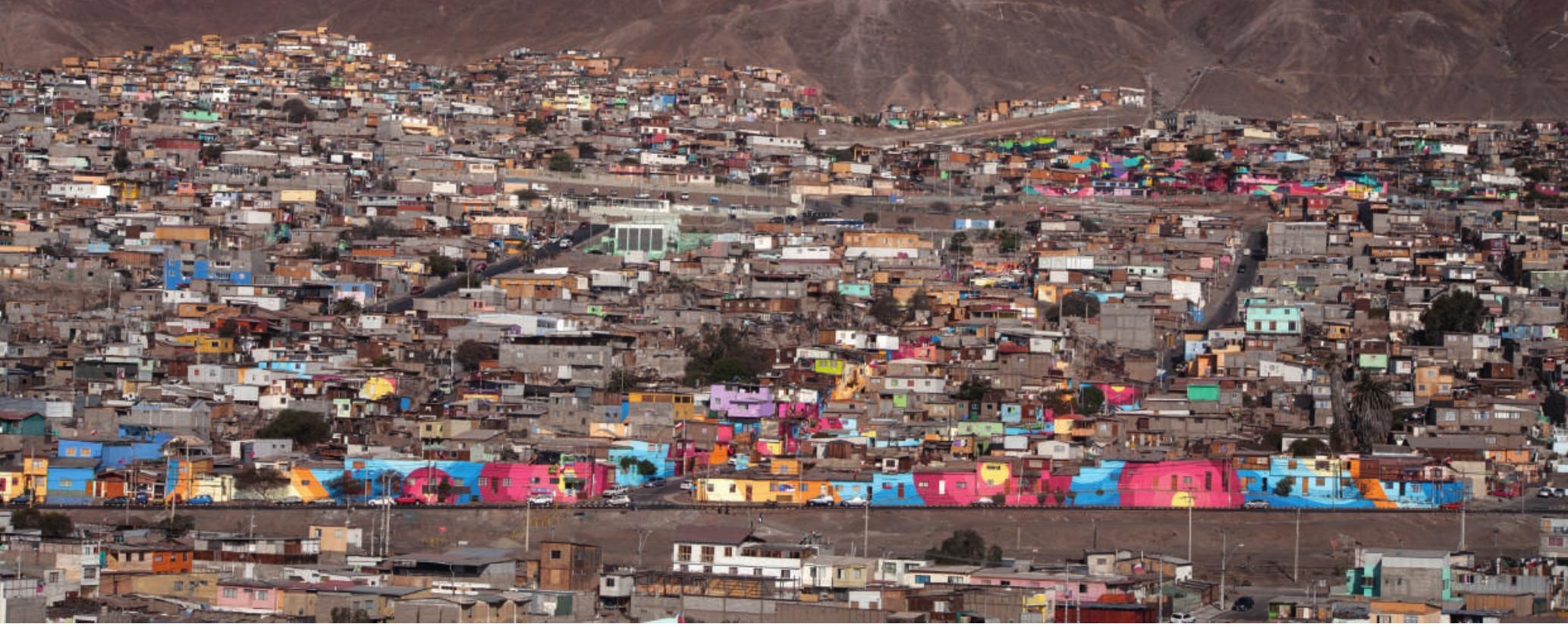

35 | The Journal of Public Space, 3 (2), 2018 | ISSN 2206-9658

City Space Architecture / UN-Habitat 


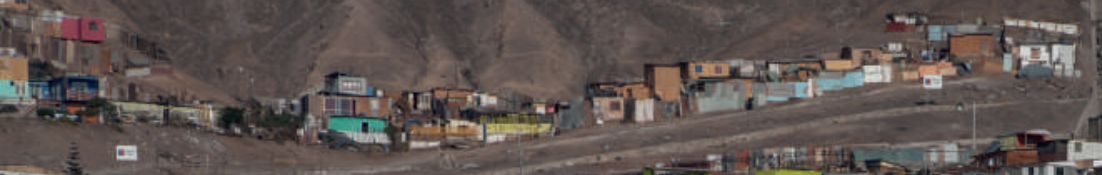

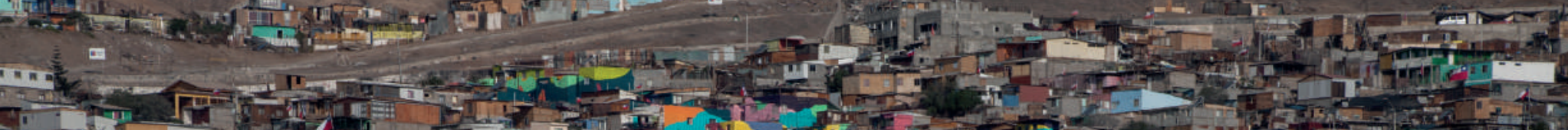

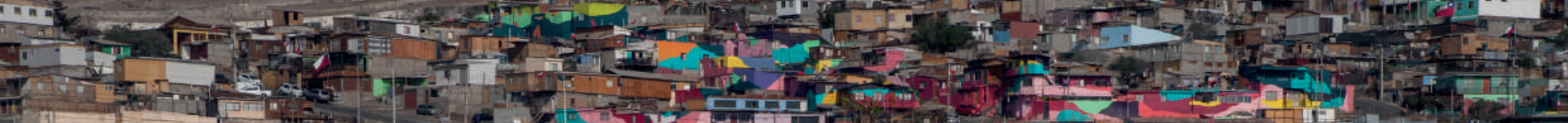

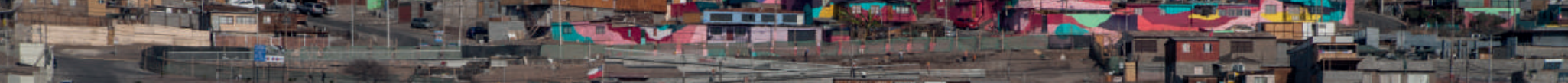
tom

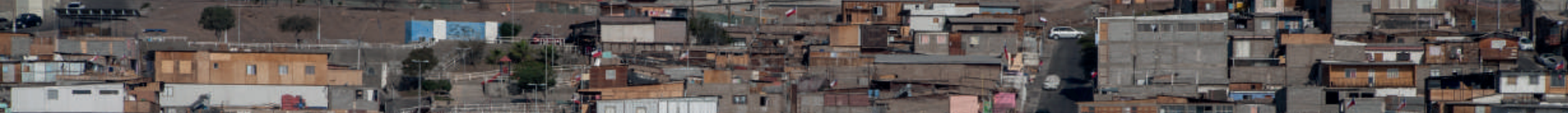

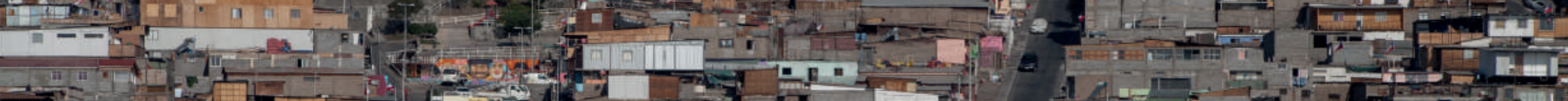

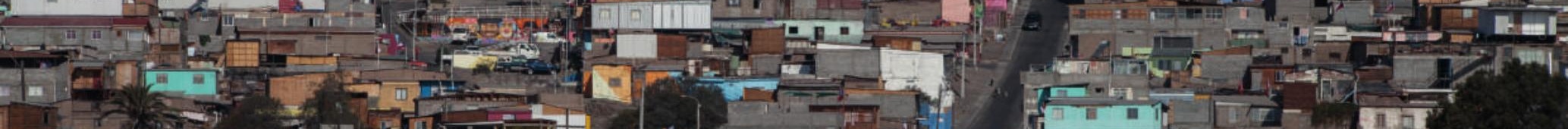

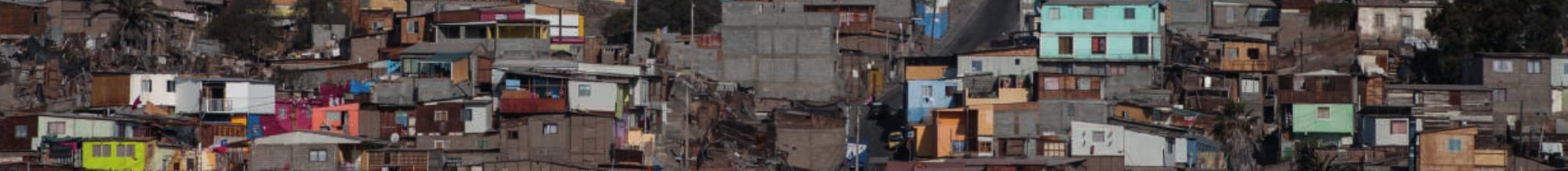

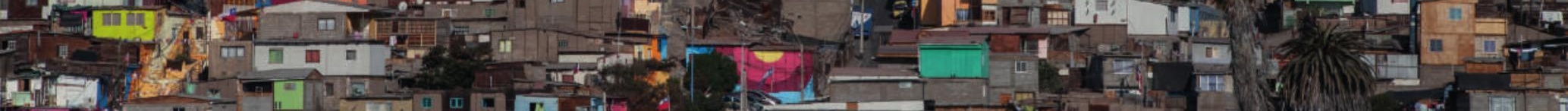

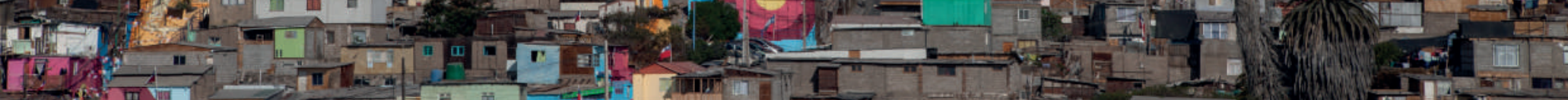

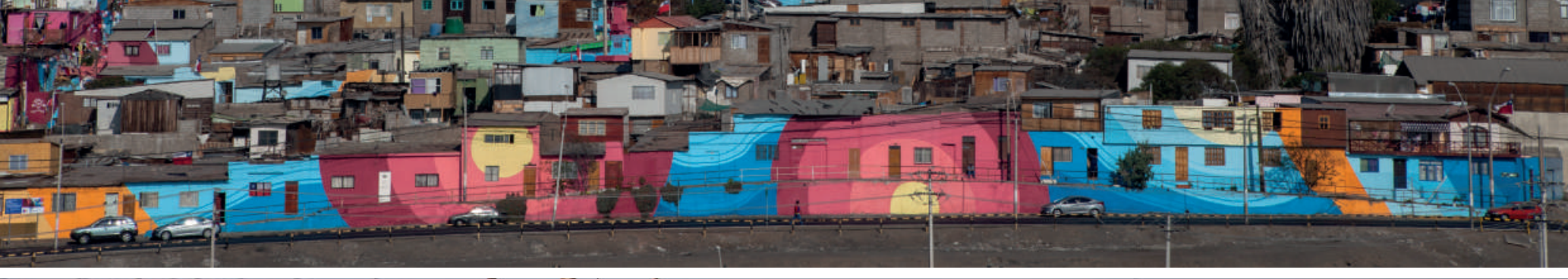

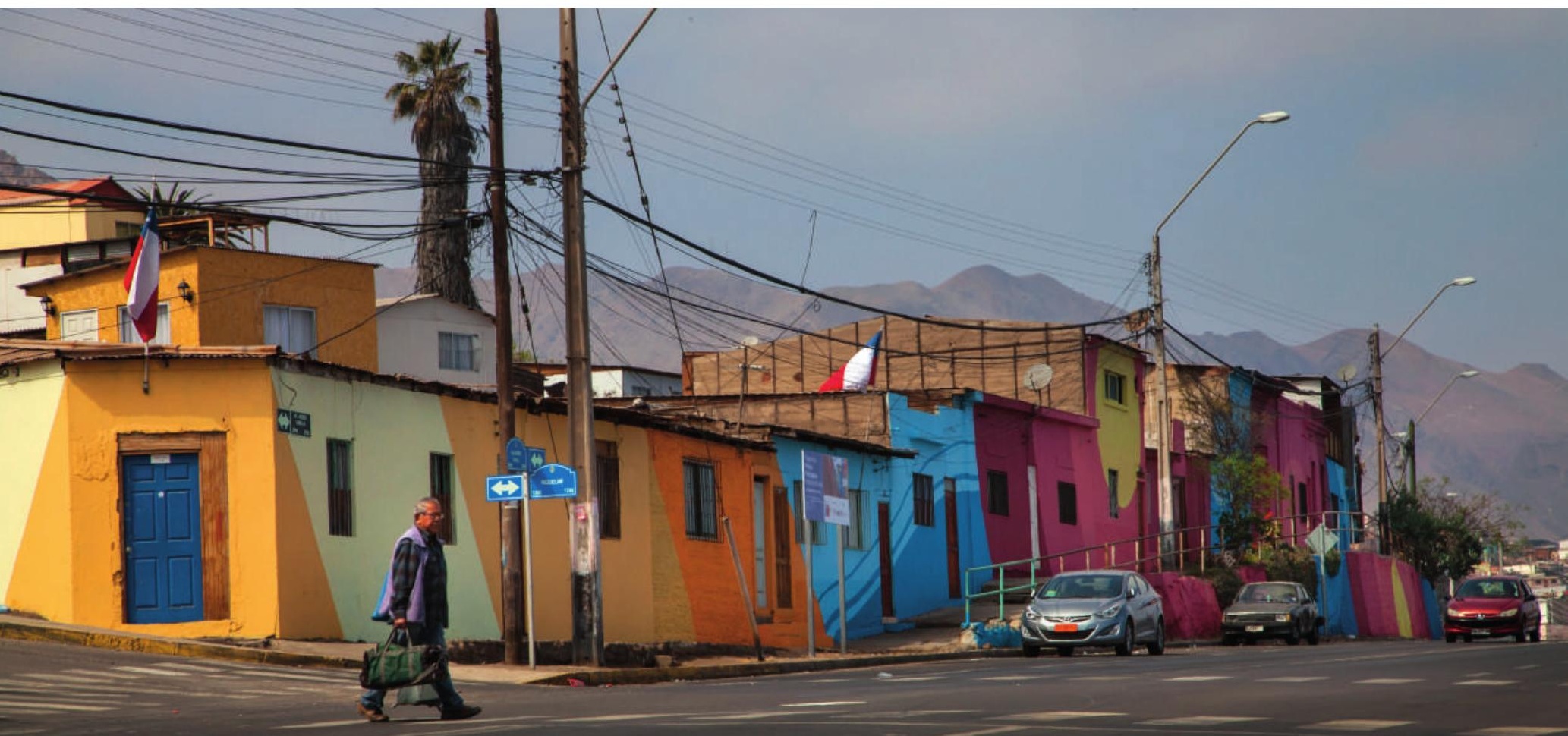


Javier Serrano Guerra, Juan Jaume Fernández, Pablo Ferreiro Mederos, Pablo Purón Carrillo

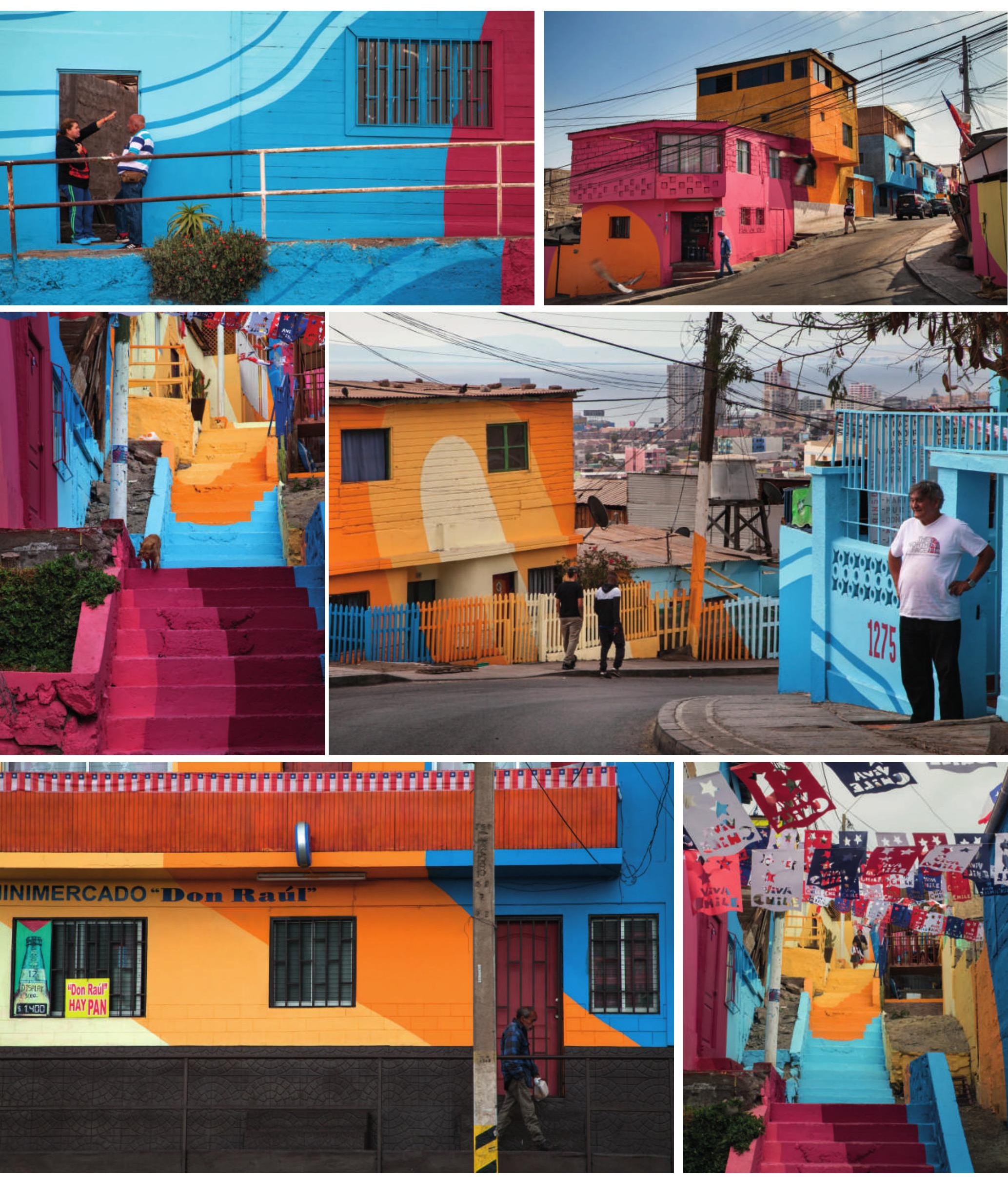

37 | The Journal of Public Space, 3 (2), 2018 | ISSN 2206-9658

City Space Architecture / UN-Habitat 

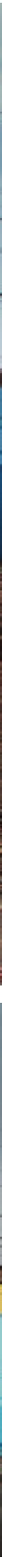

René Schneider South community, stands out for the strength of its neighbor association. Tamara and Yaque are the leaders of a neighbor group who have built up great efforts in their community. Before starting the project we held several encounters with them in their community headquarters. There we could get the bases for our concept design. Some of the drawings they did were specially inspiring.

The mineral richness of the second region soil is the key factor for the city's development, and it is essential for its future growth. This is what makes Antofagasta a unique city. We confirmed it through the neighbor queries, in which most of them mentioned mining as the main reason why all the families moved to the city.

The soil of Antofagasta poses an extremely rich color palette. We studied it in order to create our own chromatic range, interpreting the geologic section to adapt it to the urban landscape.

38 | The Journal of Public Space, 3 (2), 2018 | ISSN 2206-9658

City Space Architecture / UN-Habitat 
Javier Serrano Guerra, Juan Jaume Fernández, Pablo Ferreiro Mederos, Pablo Purón Carrillo
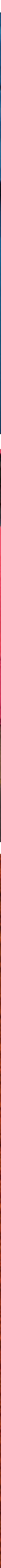

39 | The Journal of Public Space, 3 (2), 2018 | ISSN 2206-9658 

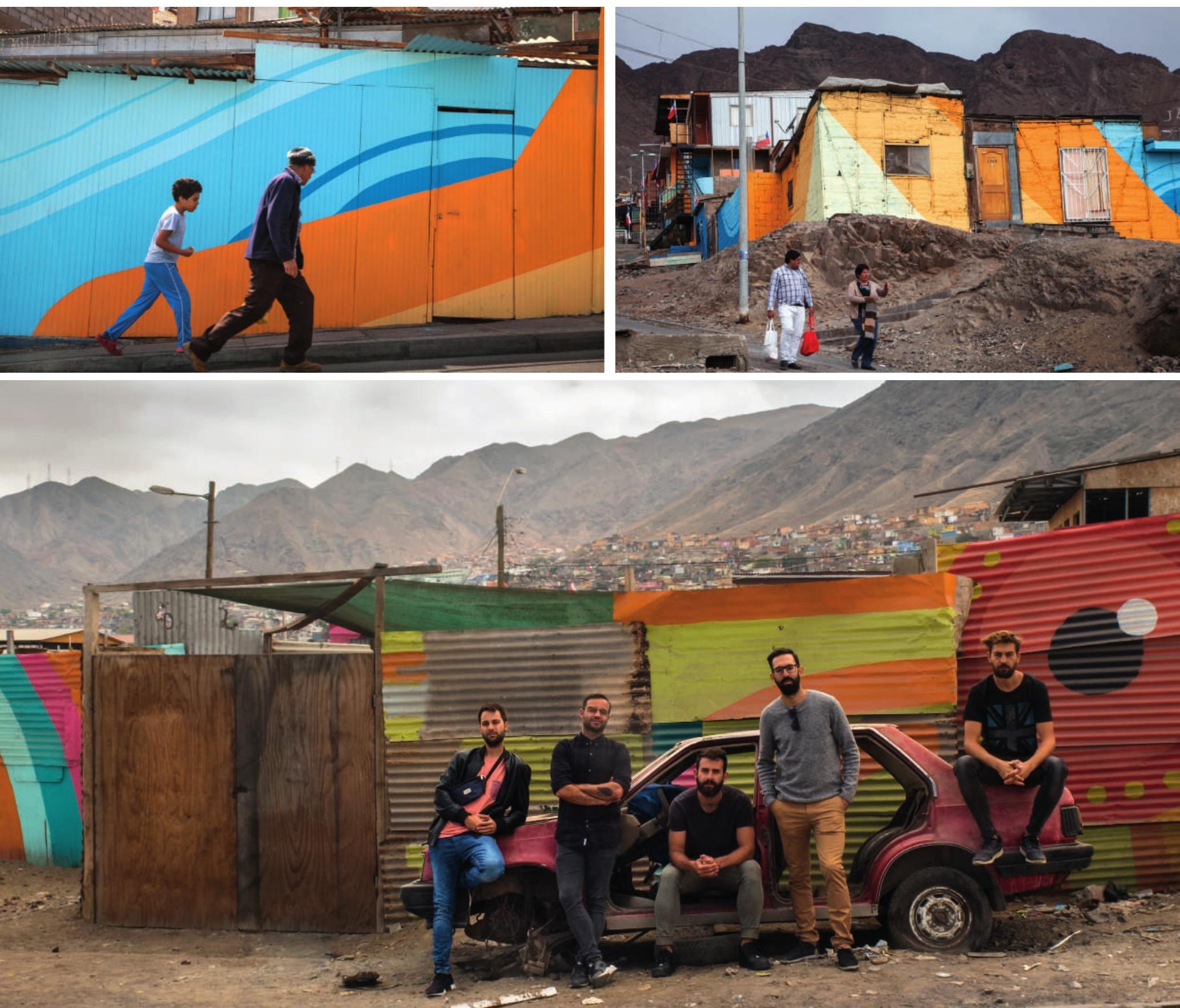

\section{Credits}

Nearly 4.000 sqm painted at the René Schneider South community.

It has been directed and financed by the development plan from the CREO Antofagasta institution. With the collaboration of Marchantes and Balmaceda Arte Joven as work field supporters and with the neighbor association from René Schneider Sur neighborhood. We want to thank Pablo López and Pancho Cooper for being the best orchestra directors we've ever had; Katy Tapia, Diana and Jean Carla for their labor and for joining together everybody at the workfield.

It's been a pleasure to work and learn from local artists Zopa, Seba Ovnie, Marte, Paulo Araya, Katica, Koté, Basco, Cristian, Gabriel, Javiera Aròstica, Jano and Juan Miranda. And to share great moments with Francesca Barrales, miss Marcia, Peka, Yesenia, Chili, Susana, Sr Pedro, Sr Osvaldo, Sr Hugo and the rest of René neighbors.

40 | The Journal of Public Space, 3 (2), 2018 | ISSN 2206-9658

City Space Architecture / UN-Habitat 